\title{
Reflexões sobre competência docente no ensino de enfermagem*
}

\author{
THOUGHTS ON TEACHING COMPETENCES IN NURSING
}

REFLEXIONES SOBRE COMPETENCIA DOCENTE EN LA ENSEÑANZA DE ENFERMERÍA

\author{
Inahiá Pinhel', Paulina Kurcgant"
}

\section{RESUMO}

Este estudo teórico-analítico tem como objetivo discutir os conceitos de competências docentes no ensino de enfermagem no Brasil, partindo do resgate, deste conceito, no mundo do trabalho. $\mathrm{O}$ ensino de enfermagem realizado em um ambiente específico, efetiva os fenômenos pedagógicos em meio a relações complexas, que ocorrem entre professor, aluno, paciente e família. Assim, o docente e o enfermeiro-educador vivenciam as atividades de ensinoaprendizagem em enfermagem, nos processos de trabalho educacional, assistencial e gerencial. Para esta nova conformação do processo de ensino-aprendizagem, é necessário que não só os novos enfermeiros, mas também os atuais e futuros enfermeiros-professores, desenvolvam competências que os possibilitem a pensar e agir com ética e ousadia

\section{DESCRITORES}

Educação baseada em competências.

Educação em enfermagem.

Docente de enfermagem.

\section{ABSTRACT}

This theoretical-analytical study is aimed at discussing the concepts of teaching competences in Nursing courses in Brazil, with the starting point being the transfer of this concept from the professional practice. Nursing education takes place in a specific environment and puts into effect the pedagogical phenomena among the complex relations that occur between instructor, pupil, patient and family. Therefore, instructors and nurse-educators experience the activities of teaching-learning in Nursing in the processes of educational, caring and management work. For such new conformation of the teaching-learning process it is necessary not only that the new nurses, but the current and future nurse-instructors as well, develop abilities that make possible for them to think and act with ethics and boldness.

\section{KEY WORDS}

Competency-based education. Education, nursing. Faculty, nursing.

\section{RESUMEN}

Este estudio teórico-analítico tiene como objetivo discutir los conceptos de competencias docentes en la enseñanza de enfermería en Brasil, partiendo del rescate, desde el concepto, en el mundo del trabajo. La enseñanza de enfermería realizada en un ambiente específico, efectiva los fenómenos pedagógicos por medio de relaciones complejas, que ocurren entre profesor, alumno, paciente y familia. Así, el docente y el enfermero-educador vivencian las actividades de enseñanza-aprendizaje en enfermería, en los procesos de trabajo educacional, asistencial y gerencial. Para esta nueva conformación del proceso de enseñanza-aprendizaje, es necesario que no solo los nuevos enfermeros, pero también los actuales y futuros enfermeros-profesores, desarrollen competencias que los posibiliten a pensar y actuar con étnica y osadía.

\section{DESCRIPTORES}

Educación basada en competencias.

Educación en enfermería.

Docente de enfermería.
Extraído da tese "O desenvolvimento de competências para a docência segundo a vivência de docentes de um curso de graduação em enfermagem", Escola de Enfermagem, Universidade de São Paulo, 2006.

I Enfermeira. Mestre em Administração em Enfermagem pela Escola de Enfermagem, Universidade de São Paulo (EEUSP). Professora da Faculdade de Enfermagem, Pontifícia Universidade Católica de Campinas (PUCAMP), Campinas, SP, Brasil. inahiap@uol.com.br

II Professora Titular do Departamento de Orientação Profissional da Escola de Enfermagem, Universidade de São Paulo (EEUSP), São Paulo, SP, Brasil. pkurcg@usp.br 


\section{INTRODUÇÃO}

O sucesso econômico decorrente da primeira revolução Industrial, com a substituição da força física do homem pela energia de máquinas, criou condições para a reordenação do processo de produção e o surgimento do modelo capitalista, ocorrendo, consequentemente, a submissão gradativa de todas as nações ao paradigma fordista-taylorista. Posteriormente, houve o esgotamento do modelo inicial e as modificações das configurações sócio-econômicas provocaram condições para a ocorrência da segunda revolução industrial, com ênfase nas capacidades intelectuais e nas chamadas competências humanas.

Visando criar condições favoráveis para sua expansão e também para a manutenção de sua condição hegemônica, o modo de produção capitalista utilizou-se da educação e do ensino como principais instrumentos de formação de profissionais e de docilização da massa trabalhadora. Nesse contexto o ensino como atividade profissional, foi se efetivando de forma ampla e complexa, na tentativa de se articular com os aspectos políticos, econômico e social das sociedades, tanto em âmbito local como nacional e internacional.

Estruturada em seus primórdios como instrumento de aculturação e voltado para a formação do caráter e socialização adequados para os novos dirigentes da sociedade, com sucessivas crises paradigmáticas, a educação passou a ser também voltada para o trabalho, tornando-se sistema de produção e reprodução de conhecimentos utilitários, buscando a modelação de aptidões técnicas, cada vez mais especializadas, destinadas a atender aos desafios dos novos desenvolvimentos tecnológicos no espaço da produção.

Desta forma, de espaço privilegiado da pesquisa, do conhecimento e de sua transmissão, a universidade passou da condição de elitista - como fundamentada no iluminismo alemão, para a situação de universidade vocacional e altamente especializada. Após refletir sobre as tensões existentes na crise da universidade pós-moderna e atual, passou a categorizá-la como sendo uma espécie de parque de estacionamento, pois

passou a acolher e deixar permanecer no seu seio por um período mais ou menos prolongado, gente que não se arrisca a entrar no mercado de trabalho com credenciais de pouco valor e que se serve da universidade como compasso de espera entre conjunturas, usando-a produtivamente para acumular títulos e qualificações que fortaleçam num momento posterior a sua posição no mercado(1).

A partir da associação entre o desenvolvimento exacerbado da microeletrônica e a expansão tecnológica-industrial, acompanhados ainda das novas descobertas na área da química fina, surgiram novas conformações do sistema de acumulação com a instalação da chamada era do conhecimento, tão decantada pelas novas práticas transnacionais e pela mundialização das economias. Essa era tem como paradigma, a valorização da informação, fazendo com que o mercado de trabalho busque profissionais não só portadores de conhecimentos relevantes e dotados de habilidades específicas, mas criativos e competentes, o que leva as universidades à buscarem novas competências nos profissionais nela formados, e consequentemente, a buscar novas competências nos docentes nela inseridos.

Os objetivos para esta nova conformação da educação, voltada para a reelaboração dos conhecimentos, para a produção de novos conhecimentos e ainda para o desenvolvimento de competências e disposição para apreensão de habilidades necessárias para o trabalho, envolvem profundas modificações nas relações professor-aluno. Essas competências

deverão expressar ações como a reflexão crítica, a curiosidade científica, a criatividade e a investigação, tendo por base a realidade dos educandos, tendo um professor a responsabilidade de articular metodologias de ensino caracterizadas por uma variedade de atividades estimuladoras da criatividade dos alunos(2).

De maneira análoga aos cursos de formação de outras profissões, o corpo docente dos cursos de Enfermagem, é constituído, em seu cerne, por profissionais de enfermagem, levados, posteriormente à condição de docentes, quando passam a enfrentar as situações e realidades pedagógicas sem que tenham tido, em sua grande maioria, oportunidades para a construção de competências voltadas para esse processo de trabalho. Dessa forma, tendo como pano de fundo as novas conformações sócio-econômicas e culturais presentes na atualidade, os saberes docentes e as competências se articulam neste processo de desenvolvimento pessoal e profissional, sendo relevante que esses docentes apreendam o conceito de competências em sua maior amplitude, com vistas à melhoria da formação das gerações seguintes de profissionais.

\section{COMPETÊNCIAS DOCENTES}

O termo competência deriva do latim competentia, possuindo etimologicamente vários significados, entre os quais a qualidade de quem é capaz de apreciar e resolver certo assunto, fazer determinada coisa, capacidade, habilidade e aptidão ${ }^{(3)}$. Dessa forma, tem sido empregado indistintamente para relacionar diretamente competência ao conceito de qualidade, de onde resulta sério desvirtuamento em seu emprego ${ }^{(a)}$.

Perpassada pelo senso comum, a noção ou o entendimento de competência é associada ao sucesso, à autoridade de um indivíduo sobre determinado assunto e ainda ao seu status quo pessoal ou na sociedade onde está inserido. Inicialmente, subjacente ao processo cultural, econômico e principalmente político, e somente mais recentemente, explicitada e merecedora de estudos mais aprofundados, a noção de compe-

(a) Também são citados pelo autor que competência significa a faculdade concedida por lei a um funcionário, juiz ou tribunal para apreciar e julgar certos pleitos ou questões, idoneidade; conhecimento lingüístico, parcialmente inato e parcialmente adquirido, que permite a um indivíduo falar e compreender a sua língua.

$\begin{array}{rr}\text { Rev Esc Enferm USP } \\ 2007 ; 41(4): 711-6 . & \text { Reflexões sobre competência docente } \\ \text { www.ee.usp.br/reeusp/ } & \text { no ensino de enfermagem } \\ \text { Pinhel I, Kurcgant } P & \end{array}$


tência permeia o processo educacional como um todo e tem grande influência sobre o papel profissional docente.

Por ser um conceito polissêmico, tanto na esfera do trabalho quanto na da educação, competência tem vários significados, entre os quais a qualidade de quem é capaz de apreciar e resolver certo assunto, de fazer determinada coisa ou possuir uma capacidade, habilidade ou aptidão, ou seja, de maneira geral, a noção de competência se apresenta sempre associada a ação. Neste sentido, o conceito da competência vem sendo enfaticamente empregado no intuito de associar o conhecimento teórico à prática, tendo como centro, o indivíduo capaz de tal realização.

É importante destacar que a noção de competência não é nova, mas seu uso tem sido difundido nos discursos sociais e científicos mais recentemente, tendo sido apropriado pelo mundo do trabalho, que o relaciona ao conceito de qualidade. Por estar relacionado à ação, o conceito de competência deve ser avaliado em função de uma determinada situação posta, pois

a palavra competência é, aliás, bem mais rica do que o uso que dela se faz atualmente, já que designa simultaneamente o direito e a capacidade de conhecer. Para conhecer os meios de compreender a maneira como as competências se diferenciam, é necessário considerá-las como produtos de processos e não mais como pontos de partida, encarando esses processos como seqüências de habilitações. Será competente aquele que está habilitado a tornar-se hábil em um domínio de conhecimento(4).

Segundo a lógica capitalista, a noção de competência representa apenas uma atualização do conceito de qualificação, o conceito representa o rejuvenescimento da teoria do capital humano e uma metamorfose do conceito da qualificação na sua conotação produtivista, ou seja, voltado para a elevação da exploração do trabalhador por parte do capital ${ }^{(5)}$.

Competência igualmente pode ser vista como o deslocamento conceitual de qualificação para competência. Para tanto, toma a qualificação como conceito central na relação trabalho-educação e discute o conceito de competência como mais objetivo por ter ordenado, historicamente, as relações sociais de trabalho e educativas, frente à materialidade do mundo produtivo. Neste sentido,

essa centralidade tende a ser ocupada, contemporaneamente, não mais pelo conceito de qualificação, mas pela noção de competência que, aos poucos constitui-se como conceito socialmente concreto. Não obstante, a noção de competência não substitui ou supera o conceito de qualificação. Antes, ela o nega e o afirma, simulta-neamente, por negar algumas de suas dimensões e afirmar outras ${ }^{(5)}$.

Essa autora, referindo-se ao mundo do trabalho, analisa que a dimensão conceitual de qualificação remete à formação e ao diploma, frequentemente perseguido como interface entre a formação e o emprego, na acepção que este garantiria uma qualificação, um status, uma remuneração. Mas, questiona a autora, isto garantiria a competência?
Segundo ela, o exercício da competência não existe sem que haja profundidade dos conhecimentos que possam ser disponibilizados e mobilizados pelo sujeito para superar determinada situação. Os conhecimentos e saberes não se limitam ao âmbito de sua aplicabilidade, mas, justamente porque implicam em um exercício reflexivo, pressupõe-se que o sujeito mobilize um conjunto de valores, aprendizagens e habilidades em favor das situações. Assim, continua a autora,

conquanto a qualificação remeta-se ao homem em suas condições históricas de produção da existência, construindo-se como conceito histórico-concreto de mediação da relação trabalho-educação, a competência, por abstrair essas múltiplas determinações da atividade humana, pode resgatar uma compreensão essencialista do trabalho, cujo centro, ao invés de ser o posto de trabalho, desloca-se para o sujeito abstraído das relações sociais ${ }^{(5)}$.

É também possível entender competência como esquemas mentais, ou seja, as ações e operações mentais de caráter cognitivo, sócio-afetivo ou psicomotor que, mobilizadas e associadas a saberes teóricos ou experiências, geram habilidades, ou seja, um saber-fazer ${ }^{(6)}$.

Na mesma direção, o documento do Ministério da Educação e Cultura define competências como sendo

as modalidades estruturais de inteligência, ou melhor, as ações e operações que utilizamos para estabelecer relações com e entre objetos, situações, fenômenos e pessoas que desejamos conhecer. As habilidades decorrem das competências adquiridas e referem-se ao plano imediato do saber-fazer. Por meio das ações e operações, as habilidades aperfeiçoam-se e articulam-se, possibilitando nova reorganização das competências ${ }^{(7)}$.

Considerando os conteúdos concretos do trabalho, identifica-se a competência de processo (relativa ao deslocamento da atenção do trabalhador da conduta individual das máquinas, para os processos de trabalho), a competência técnico-performativa (relativa ao desenvolvimento de uma visão de gestão do trabalho), a competência sobre a organização (que possibilita e é resultante da anterior, permitindo a reelaboração de objetivos a partir de parâmetros e princípios da organização produtiva), a competência de serviço (implica o trabalhador perguntar-se sobre o impacto provocados direta ou indiretamente por seus atos profissionais nas vidas dos usuários, ou a utilidade dos serviços para os usuários finais) e a competência social (saber-ser ou comportamentos e atitudes do trabalhador, sua autonomia, responsabilidade e capacidade de comunicação com o ambiente social ${ }^{(5)}$.

O conceito de competência de ação seria composto pela competência técnica (domínio de conhecimentos e destrezas necessários para a realização eficiente e profissional de tarefas em uma área de trabalho), competência metódica (relacionada à capacidade de reação adequada face às tarefas laborais e desvios surgidos, descobrindo autonomamente as 
vias de solução, transferindo de forma sensata as experiências colhidas para outros problemas de trabalho), competência social (envolve a colaboração e cooperação com outras pessoas, referindo às relações humanas), e a competência participativa (relacionada à co-organização do trabalho de forma construtiva do trabalho e do ambiente de trabalho e capacidade de organizar e decidir de forma atuante, assumindo responsabilidades $)^{(5)}$.

Outra visão sobre competência é entendê-la como uma forma de interpretar o mundo, classificando-a em três dimensões: competências técnicas (que permitem interpretar os processos físicos e organizacionais), competências subjetivas (que permitem interpretar as relações pessoais e interpessoais) e as competências sociais (que permitem interpretar o que ocorre no mercado, no espaço público $)^{(5)}$.

Especificamente no ambiente da educação, competência docente é referida como sendo uma capacidade de agir eficazmente em um determinado tipo de situação, apoiada em conhecimentos, mas sem limitar-se a eles possibilitando que o professor ponha em ação e em sinergia, vários recursos cognitivos complementares, entre os quais estão os conhecimentos. Ainda segundo esse autor, é a competência docente que permite ao professor enfrentar um ou mais tipos de situações, realizando operações mentais complexas voltadas para a determinação e realização de uma ação relativamente adaptada para a situação vivenciada ${ }^{(8-9)}$.

Sob esta ótica, a competência docente está associada não apenas aos saberes (conhecimentos) que o professor precisa ter, mas também intimamente ligada às capacidades e habilidades que, em situações complexas e principalmente em tempo real, permitem eclodir esquemas de pensamento que possibilitem a mobilização, a orquestração e a sistematização de recursos pertinentes para a aplicação destes saberes. Isto se deve porque

o saber dos professores é plural, composto e heterogêneo, porque envolve, no próprio exercício do trabalho, conhecimentos e um saber-fazer bastante diverso, proveniente de fontes variáveis e, provavelmente, de naturezas diferentes ${ }^{(10)}$.

Assim, com base nos pressupostos e conceitos dos autores visitados, depreende-se que competência é uma categoria complexa de atividade mental e intelectual que reúne a capacidade e a habilidade do trabalhador em mobilizar conhecimentos e recursos mentais para resolver situações complexas que ocorrem na vida profissional. Nesta direção, na docência, a competência é construída na medida em que estas operações mentais são realizadas em tempo real, isto é, quando há a mobilização dos atributos, conhecimentos, vivências e recursos mentais, que se efetuam, instantaneamente, no momento da solicitação. Ao mesmo tempo, competência pode ser considerada como a essência da docência, já que essência significa aquilo que é o mais básico, o mais central, a mais importante característica de um ser ou de algo, que lhe confere uma identidade, um caráter distintivo.
Como a educação é um sistemático e intencional processo histórico de interação com a realidade por meio do relacionamento humano, baseado no trabalho com o conhecimento e realizado sob a mediação do professor, com a finalidade de colaborar com a formação do estudante em sua totalidade, o docente, a partir e com a utilização de suas competências, busca proporcionar condições que possibilitem a produção de sentido, que é uma construção do sujeito da ação pedagógica: o estudante $^{(11)}$. Reconhece-se, portanto, que a formação profissional do docente como fruto de uma construção histórica, necessariamente imbricada com a unidade de ensino, pois

\begin{abstract}
o saber dos professores não é um conjunto de conteúdos cognitivos definidos de uma vez por todas, mas ao contrário, um processo em construção ao longo de uma carreira profissional na qual o professor aprende progressivamente a dominar o seu ambiente de trabalho, ao mesmo tempo em que se insere nele e o interioriza por meio de regras de ação que se tornam parte de sua "consciência prática"(10).
\end{abstract}

Analisando a trajetória profissional dos docentes, esse autor afirma que os momentos iniciais de suas carreiras resultam reprodutivistas, pois é resultante da vivência escolar dos futuros professores em seu futuro ambiente de trabalho, o que os leva, antes mesmo de começarem a ensinar, já conhecerem de muitas formas, como é o ensino em decorrência de sua vida escolar anterior. Desta forma, a trajetória de vida faz com que o professor trate o conhecimento de forma similar com a que recebeu e da mesma forma com que vivenciou suas experiências escolares ${ }^{(10)}$.

Esta situação decorre da temporalidade da formação do indivíduo, que segundo o autor, se aplica não só à esfera profissional e escolar, mas também diretamente à sua carreira,

compreendida como um processo temporal marcado pela construção do saber profissional. Esse tema da carreira profissional, por sua vez, incide sobre temas conexos como a socialização profissional, a consolidação da experiência de trabalho inicial, as fases de transformação, de continuidade e ruptura que marcam a trajetória profissional, as inúmeras mudanças (de classe, de escola, de nível de ensino, de bairro, etc.) que ocorrem também no decorrer da carreira profissional e, finalmente, toda a questão da identidade e da subjetividade dos professores, que se tornam o que são de tanto fazer o que sabem ${ }^{(10)}$.

Em decorrências das transformações ocorridas nas sociedades capitalistas nas últimas décadas, comandadas pela lógica do consumo, os saberes passaram a ser definidos em função das pressões dos consumidores e da evolução, mais ou menos tortuosa, do mercado de trabalho, modificando a função primordial dos professores - formar indivíduos cidadãos, voltando-se para equipá-los para atendimento aos ditames do mercado de trabalho. Ao invés de formadores, os professores seriam muito mais informadores ou transmissores de informações potencialmente válidas e utilizáveis pelos clientes dos cursos disponibilizados pelas instituições de ensino ${ }^{(12)}$, por serem possuidoras de realidades contex- 
tualizadas, com valores que variam segundo as condições históricas e sociais que a envolvem, determinam o perfil dos egressos e dos seus docentes de onde resulta que,

o professor, com relação à escola é, ao mesmo tempo, determinante e determinado. Assim como seu modo de agir e de ser, recebem influências do ambiente escolar, também influencia o mesmo ambiente ${ }^{(12)}$.

Nesta direção, as esferas governamentais do Brasil procederam, nos últimos anos, à reorganização das políticas sociais, especialmente com relação aos sistemas previdenciário e de saúde pública, ocasião em que a Enfermagem redefiniu suas práticas, havendo o deslocamento da intervenção sobre o doente para a atenção ao sadio. Assim,

Nas instituições de ensino, passou-se a discutir a formação do enfermeiro generalista, adequado para esse novo modelo de atenção à saúde, com característica de simplificação, extensão de cobertura, atividades preventivas e ambulatoriais e de integração multidisciplinar e multiprofissional. [...] Esse período deu início ao movimento de libertação da produção do saber em enfermagem. Wanda Horta, no Brasil, e as teoristas americanas, ainda que de forma incipiente, construíram as condições de possibilidade para a emergência de um novo paradigma ${ }^{(13)}$.

\section{CONCLUSÕES}

Devido às suas peculiaridades, o ensino de enfermagem é realizado em um ambiente social específico ligado ao sistema de saúde, onde os fenômenos pedagógicos são realizados por meio de uma relação dimensionalmente complexa, na medida em que além do professor e aluno, existe a pessoa do paciente.

Esta conformação faz com que, ao sujeito da ação pedagógica, seja necessário algo mais do que a formação técnica e científica, representado pela inclusão de uma formação ética, obrigando que o professor assuma de forma competente, esta função, voltada para a transformação social. Nessa direção, há demonstrações de preocupações com o processo de formação dos enfermeiros nas instituições de ensino superior, e sugere-se que sejam viabilizadas formas de inovações, pois,

entendendo que a graduação em enfermagem tem influência direta na determinação do perfil do profissional, percebo que os órgãos de formação deveriam refletir mais sobre o seu papel e propiciar espaço de discussão envolvendo todos os segmentos - docentes, acadêmicos, egressos, a fim de inovar, e coletivamente, proceder às mudanças necessárias na estrutura atual ${ }^{(14)}$

A busca do saber em Enfermagem aproxima a prática da enfermagem à prática da educação, na medida em que o enfermeiro, na condição de educador, utiliza o processo ensino/ aprendizagem em todas as suas ações de cuidado, encaradas como sendo aquelas dirigidas não só ao paciente e família, mas também aos alunos, à equipe de enfermagem e aos procedimentos técnicos. Dessa forma, requer, dos enfermeiros, uma competência reflexiva em busca de uma ação mais efetiva. Para tanto, a graduação em enfermagem não pode ser direcionada apenas pela lógica do mercado de trabalho, pois

encaminhar o ensino de graduação apenas do ponto de vista do mercado é tratá-lo sob a ótica do lucro, do capital, negando a natureza mesma do processo educativo. É privilegiar o saber imediato, quase instantâneo, o aprendizado da execução, do saber-fazer, a urgência, a eficiência e a eficácia típicas do mercado como elementos norteadores de nosso trabalho, em detrimento do cultivo do raciocínio, da reflexão, da criação, ou seja, caminhar no sentido oposto ao da humanização do homem(15).

Assim, a formação profissional pretendida para os egressos dos cursos de enfermagem é mais aberta e dialógica e ao mesmo tempo crítica; mais flexível e ao mesmo tempo mais rigorosa; solidamente alicerçada em conhecimentos e principalmente, fundamentada na ética, voltada para o desenvolvimento do raciocínio, da autonomia, da criatividade, da comunicação e da capacidade de identificar problemas e buscar alternativas para superá-los. Somente assim, o estudante estará construindo suas competências e habilidades voltadas para a superação dos conflitos existenciais e éticos, bem como para o enfrentamento dos desafios que a convivência social e o mundo do trabalho apresentarão, no decorrer de sua trajetória de vida.

\section{É marcante a presença de conflitos existenciais profissionais provocados pela não confluência dos referenciais filosóficos e pragmáticos construídos durante a formação circunscritos à interação com aqueles requeridos pelo mercado de trabalho mais pertinentes à intervenção. Os egressos dos cursos de enfermagem nutrem o ideal de se realizarem no modo-de- ser-cuidado, enquanto a grande maioria das instituições hos- pitalares estão modeladas no modo-de-ser-trabalho privile- giando a intervenção, a produção e a dominação ${ }^{(16)}$.}

Ao ensino de graduação compete o questionamento e rompimento com todo e qualquer moralismo, superando a éti$c a$ das aparências, do momento, das circunstâncias, dos interesses, dos valores e conveniências de indivíduos, grupos e corporações, que é inseparável dos desmandos, da prepotência, da dominação, da exclusão sócio-econômica-política e cultural, que subverte e rompe com os princípios fundamentais na existência individual e coletiva e no exercício profissional: a verdadeira ética ${ }^{(15)}$.

A ética, pelo contrário, expressão da verdade, do bem, da liberdade, da autonomia, de valores e necessidades humanas universais, transcendentes e permanentes - é um chamamento à superação da prepotência, do legalismo, do moralismo, e à construção da utopia de uma sociedade completamente diferente(15).

Pelas reflexões feitas, conclui-se que as competências docentes são construídas ao longo das trajetórias pessoais e profissionais do professor, no cotidiano do trabalho, expandido para além da sua área técnica de formação, invadindo os espaços sociais das relações interpessoais, tanto na sociedade, quanto nas instituições de ensino. Como o pro- 
fessor nasce e está imerso em seu cotidiano historicamente vivenciado, constrói suas competências acionando seus mecanismos pessoais, trabalhando com conhecimentos já existentes e buscando interagir com as normas e regras vigentes na sociedade no momento em que está vivendo. Assim, no caso da enfermagem, a construção das competências docentes se dá ao longo de um processo de contínua capacitação profissional, voltado para a construção de um perfil enquanto profissional de enfermagem ligado à docência, perfil este que está em constante transformação.

As conformações da sociedade e do mundo do trabalho, ao longo do processo histórico, influenciam e moldam as estruturas das unidades de ensino, determinando as relações com as competências. Neste sentido, as transformações nos cursos de enfermagem ensejam o desenvolvimento de novas competências docentes, não só relativas a conhecimentos técnico-científicos, mas também as relacionadas às atividades pedagógicas intrínsecas aos docentes, envolvendo a comunicação, a autonomia intelectual, a capacidade auto-reflexiva e de autocrítica. Essas capacidades possibilitam a retroatuação para superação de questões e conflitos e a descoberta autônoma das vias de solução, de viabilização de adoção de experiências anteriores na solução de problemas do trabalho, com amplo aspecto social e coletivo.

Contudo, apenas as competências e habilidades vinculadas ao saber-fazer não são suficientes para a ocupação efetiva e qualificada de um espaço profissional, para o

\section{REFERÊNCIAS}

1. Santos BS. Pela mão de Alice: o social e o político na pósmodernidade. $4^{a}$ ed. São Paulo: Cortez; 1997.

2. Faria JIL. Prática docente reflexiva na disciplina de administração de enfermagem hospitalar: uma experiência de desenvolvimento profissional de professores-pesquisadores [tese]. Ribeirão Preto: Escola de Enfermagem de Ribeirão Preto, Universidade de São Paulo; 2003.

3. Ferreira $\mathrm{ABH}$. Novo dicionário da língua portuguesa. $2^{\mathrm{a}}$ ed. Rio de Janeiro: Nova Fronteira; 2001.

4. Stroobants M. A visibilidade das competências. In: Tanguy L, Ropé F. Saberes e competências: o uso de tais noções na escola e na empresa. $3^{a}$ ed. Campinas: Papirus; 2002.

5. Ramos MN. A pedagogia das competências: autonomia ou adaptação? 2a ed. São Paulo: Cortez; 2002.

6. Berger R. Formação baseada em competências numa concepção inovadora para a formação tecnológica. In: $5^{\circ}$ Congresso de Educação Tecnológica dos Países do Mercosul; 1998; Pelotas, BR. Pelotas: ETF; 1998.

7. Brasil. Ministério da Educação e Cultura. Documento Básico do ENEM: 2000. Brasília: INEP; 1999.

8. Perrenoud P. Construir as competências desde a escola. Porto Alegre: Artes Médicas; 1999.

9. Perrenoud P. Dez novas competências para ensinar. Porto Alegre: Artes Médicas; 2000. alcance da autonomia correspondente e para o reconhecimento profissional em uma dada organização de saúde. As competências relacionadas ao aprender a aprender $\mathrm{e}$ ao aprender a ser, aprender relacionar-se e melhor conviver, são essenciais na gestão dos serviços de saúde ${ }^{(16)}$.

Assim, estará sendo concretizado um novo modo de pensar e de agir na educação em enfermagem, objetivando a melhoria no atendimento das demandas sociais, com a construção de competências ético-sociais, envolvendo a capacidade de colaboração e cooperação com o outro (estudantes, usuários, docentes e demais profissionais), estabelecendo relações humanas participativas e construtivas, assumindo a responsabilidade de ser um agente transformador social sob a égide da ética, especialmente a ética no cuidado, respeitando a autonomia, a diversidade e a responsabilidade nas relações com o outro.

Para esta nova conformação do processo de ensino-aprendizagem, é necessário que não só os novos enfermeiros, mas também os atuais e futuros enfermeiros-professores, desenvolvam competências que os possibilitem a pensar e agir com ética e ousadia. Ética e ousadia não se conflitam, mas, ao contrário, produzem qualidade política, que em oposição à qualidade formal (voltada apenas para o aspecto instrumental), é voltada, pensada e dirigida para a qualidade ambiental do ser humano em formação, aquela que vai proporcionar os conceitos fundamentais da construção do conhecimento como elemento de crescimento social, com base na ética social ${ }^{(17)}$.

10. Tardif M. Saberes docentes e formação profissional. $3^{\mathrm{a}}$ ed. Petrópolis: Vozes; 2002.

11. Vasconcellos CS. Para onde vai o professor? Resgate do professor como sujeito de transformação. $8^{\mathrm{a}}$ ed. São Paulo: Libertad; 2001.

12. Cunha MI. O bom professor e sua prática. $16^{\mathrm{a}}$ ed. Campinas: Papirus; 2004.

13. Geib LTC, Migott AMB, Carvalho RMA, Mocinho RR. Os rituais de poder na educação formal do enfermeiro. Texto Contexto Enferm. 1999;8(1):80-92.

14. Fernandes GFM, Vaz MRC. Processo de avaliação humanizado e participativo nos estágios supervisionados de enfermagem. Texto Contexto Enferm. 1999;8(1):106-21.

15. Coêlho IM. Graduação: rumos e perspectivas. RAIES Rev Avaliação. 1998;3(3):15-21.

16. Ciampone MHT, Kurcgant P. Gerenciamento de conflitos e negociação. In: Kurcgant P, coordenadora. Gerenciamento em enfermagem. Rio de Janeiro: Guanabara Koogan; 2005. p. 54-65.

17.Bartolomei R. Ensinando em tempos de incerteza: a re-significação de erro em busca da melhoria da qualidade do ensino. Rev Educ PUC Campinas. 2004;(17):15-35. 